\title{
WELDABILITY OF DIRECTIONALLY SOLIDIFIED TMS-75 AND TMD-103 SUPERALLOYS
}

\author{
Y.L. Wang, X. Yu, N.L. Richards \& M.C. Chaturvedi \\ Department of Mechanical \& Manufacturing Engineering, \\ University of Manitoba, Winnipeg, Canada, R3T 5V6
}

Keywords: TMS-75, TMD-103, $\gamma / \gamma^{\prime}$ eutectic, Carbide, Liquation cracking.

\begin{abstract}
The weldability of four directionally solidified alloys TMS-75 (Base), Base $+B$, Base $+\mathrm{C}$ and TMD-103 (Base $+\mathrm{B}+\mathrm{C})$ were investigated by bead-on-plate electron beam welding, and the heat affected zone (HAZ) microstructures obtained during welding were characterized by optical microscopy and analytical electron microscopy. The presence of $\gamma / \gamma^{\prime}$ eutectic was observed to be mainly responsible for the cracking in the HAZ, although other mechanisms such as the constitutional liquation of carbides also made some contribution to it. The $\mathrm{C}$ addition improved the cracking susceptibility in HAZ appreciably, while B addition showed a detrimental effect on it, however the $\mathrm{C}$ addition to Base $+\mathrm{B}$ alloy, completely attenuated the deleterious effect of B. The cracking modes and the mechanisms of the effects of $\mathrm{C}$ and $\mathrm{B}$ additions on the weldability could be rationalized on the basis of various microstructural constituents present in the four alloys.
\end{abstract}

\section{Introduction}

The National Institute for Material Science (NIMS) of Japan has developed the third generation of single crystal (TMS-75) and DS cast (TMD-103) Ni-base superalloys containing $5 \mathrm{wt} \%$ Re. The chemistry of TMD-103 is basically the same as that of TMS-75, but it contains the grain boundary strengthening elements B and C. The research carried out by Harada's research group, which also developed these alloys, has clearly demonstrated their superior properties at elevated temperatures as compared to the current single crystal and DS cast superalloys [1-4]. In addition, these alloys have a high volume fraction of $\gamma$ ' because of their higher Al content, which also provides them very good hot corrosion resistance in spite of the low $\mathrm{Cr}$ content.

Both $\mathrm{C}$ and $\mathrm{B}$ are believed to improve high temperature rupture properties, especially with the carbides in grain boundaries. However, MC type carbides are known to make many nickel base superalloys susceptible to heat affected zone (HAZ) microfissuring in welds through constitutional liquation, although the presence of $\mathrm{Ta}$ in this superalloy is likely to increase the stability of the $\mathrm{MC}$ carbide as compared to $\mathrm{Nb}$ rich carbides present in superalloys like IN718. B additions may or may not result in the presence of borides in the microstructure. Benhaddad et al [5], for example, found significant levels of borides in a series of experimental IN718 alloys containing additions of $\mathrm{C}, \mathrm{B}$ and $\mathrm{P}$. These borides were $\mathrm{M}_{3} \mathrm{~B}_{2}$ type, rich in $\mathrm{Nb} / \mathrm{Mo} / \mathrm{Cr}$ and $\mathrm{Fe}$. Often boride phases are, however, not observed in B containing alloys, or it may be present in association with MC carbides.

As for the effects of $\mathrm{C}$ and $\mathrm{B}$ additions on the weldability of Nibase superalloys, several investigations have been done, especially on Inconel 718 [5-8]. The study by Bendadad et al [5] showed that $\mathrm{C}$ has minimal effect on the weldability of 718 , whereas, B has a significantly negative effect on the weldability, but $\mathrm{C}$ mitigates the harmful effects of $\mathrm{B}$. Further, it was suggested by Kelly [6] using a statistical analysis, that the most influential element in the micocracking of the HAZ in structural castings (IN718) of Ni-base superalloys was B. It is one of the lighter elements and is very difficult to detect accurately, particularly when it is still in solid solution. However, Huang et al also working on cast alloy IN718, showed via a careful series of heat treatments combined with B segregation analysis by secondary ion mass spectroscopy (SIMS) that B was responsible for HAZ micro-fissuring in the alloy $[7,8]$. Similar work by Chen et al [9] and Guo et al [10] on wrought IN718 also showed that B was again the main culprit in HAZ micro-fissuring.

One of the alloys developed by Dr. Harada's group, TMD-103 contains significant amount of C $(0.07 \%)$ and B $(0.015 \%)$. Since in-service damage to the parts made of these alloys are likely to be repaired by welding, as is the case with other superalloy parts, and $B$ has been shown to adversely effect the weldability of superalloys, a research project was initiated to evaluate the weldability of TMD-103 alloy and compare it with that of TMS75. To isolate the effect of B from that of Carbon on weldability of these alloys, weldability of two additional alloys, TMS-75+B and TMS-75+C, was also evaluated.

\section{Experimental}

Four alloys were DS cast by NIMS, Tsukuba, Japan into $12 \mathrm{~mm}$ diameter ingots with their axes along the $<100>$ crystallographic direction, and supplied to us by Dr. Harada. The ingots were identified as: TMS-75 (Base), Base+B, Base+C and TMD-103 $(\mathrm{Base}+\mathrm{B}+\mathrm{C})$ and their nominal chemical composition is listed in Table I. All the four alloys were given the standard NIMS heat treatment consisting of $1225^{\circ} / 1$ hour $+1275^{\circ} \mathrm{C} / 5$ hours followed by water quench.

Table I Nominal composition of the alloys investigated (wt $\%$ )

\begin{tabular}{|l|l|l|l|l|l|l|l|l|l|l|l|l|}
\hline Alloy & $\mathrm{Ni}$ & $\mathrm{Co}$ & $\mathrm{Cr}$ & $\mathrm{Mo}$ & $\mathrm{W}$ & $\mathrm{Al}$ & $\mathrm{Ta}$ & $\mathrm{Hf}$ & $\mathrm{Re}$ & $\mathrm{C}$ & $\mathrm{B}$ \\
\hline Base & Bal. & 12 & 3 & 2 & 6 & 6 & 6 & 0.1 & 5 & 0 & 0 \\
\hline Base + B & Bal. & 12 & 3 & 2 & 6 & 6 & 6 & 0.1 & 5 & 0 & 0.005 \\
\hline Base + C & Bal. & 12 & 3 & 2 & 6 & 6 & 6 & 0.1 & 5 & 0.03 & \\
\hline Base + B + C & Bal. & 12 & 3 & 2 & 6 & 6 & 6 & 0.1 & 5 & 0.07 & 0.015 \\
\hline
\end{tabular}




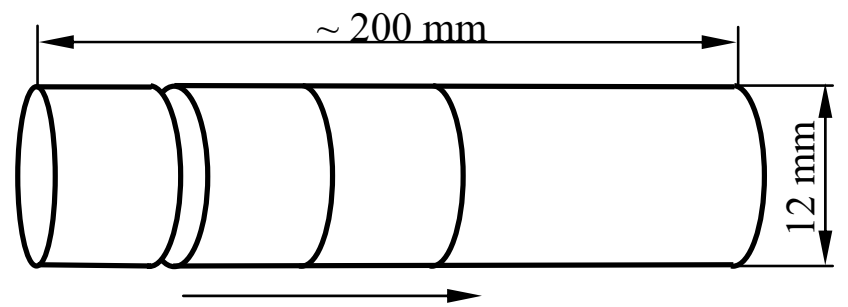

(a) Solidification direction

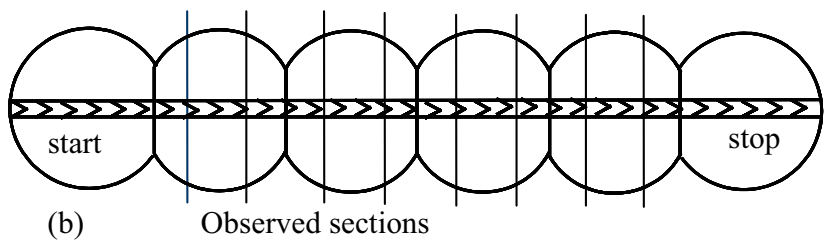

Fig. 1 Schematic diagram of electron beam welding specimens

Test samples were cut from the heat-treated DS rods by electrodischarge machining as shown in Fig 1a, and the recast layer was ground off. The cut samples were assembled for welding by tackwelding together using GTA welding techniques and one such assembly is shown in Fig. 1b. These samples were electron beam welded (EBW) using a Sciaky Mark VII welder at Bristol Aerospace, Winnipeg, using the following process parameters: 44 $\mathrm{kV}, 13 \mathrm{~mA}, 25 \mathrm{~cm} / \mathrm{min}$, with a 'sharp' focus. On the average 8 sections were cut from each welded sample and then metallographically prepared by polishing. Weldability of alloys was evaluated by measuring the length of each crack present in these 8 cross sections, and is expresses as average total crack length (Av.TCL). The Av.TCL was computed by calculating the average of the total length of all the cracks in each section.

Metallographic assessment was carried out optically and via a JEOL JSM-5900 SEM, equipped with Oxford ultra thin window EDS detector. Semi-quantitative analysis was done by using an Oxford-INCA EDS analysis software. Transmission electron microscopy analysis of carbon extraction replicas was carried out using a JEOL 2000FX microscope operating at $200 \mathrm{KV}$ and equipped with a TN5400 EDS system.

Etching for optical metallography was carried out using a solution containing: $1 \mathrm{HNO}_{3}: 3 \mathrm{HCL}: 4 \mathrm{C}_{3} \mathrm{H}_{8} \mathrm{O}_{3}$. Hardness measurements were carried out using five impressions per specimen using a Vickers hardness machine and reported as VPN.

\section{Results}

\section{Metallography of Alloys}

Optical micrographs of the as cast alloys (Fig. 2a-d) showed the presence of a dendritic structure and an aligned $\gamma / \gamma^{\prime}$ eutectic constituent; the carbon containing alloys also showed the presence of a MC carbide. In the solution treated condition, Fig 3(a-d), the $\gamma / \gamma^{\prime}$ eutectic was still present, along with carbides in the two C containing alloys. TEM analysis of these carbides extracted on carbon replicas revealed them to correspond to Ta-rich MC-type carbides with an FCC crystal structure and a lattice parameter $4.45 \mathrm{~nm}$. Fig 4 shows a TEM micrograph of the carbides, along with the TEM SAD pattern with a [100] zone axis (4b). The analysis of the metallic components of the carbide, Fig 4 (c,d), shows the MC carbide to be rich in Ta along with smaller amounts

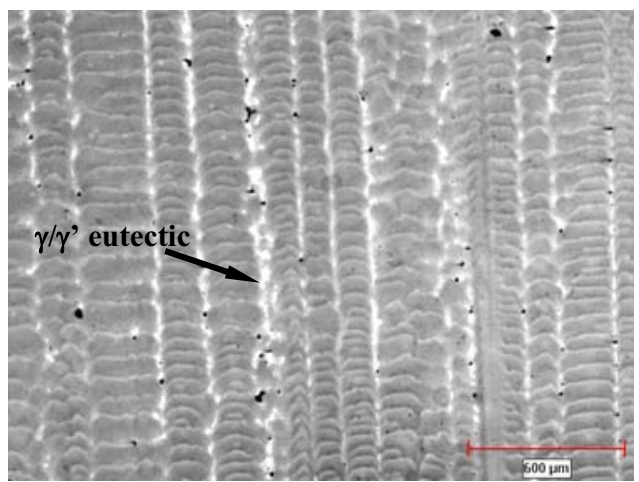

(a) Base

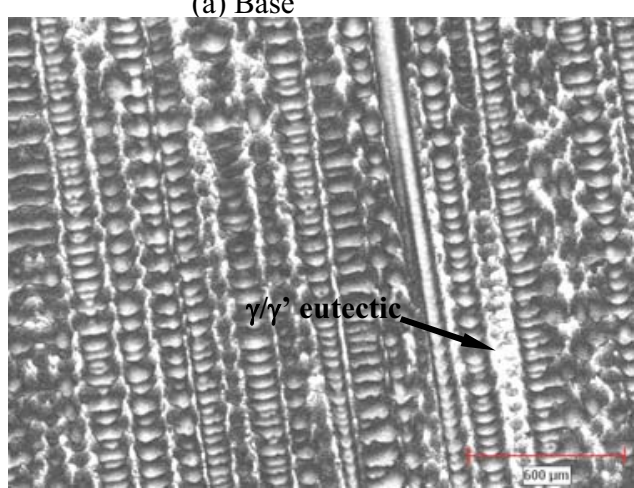

(b) Base+B

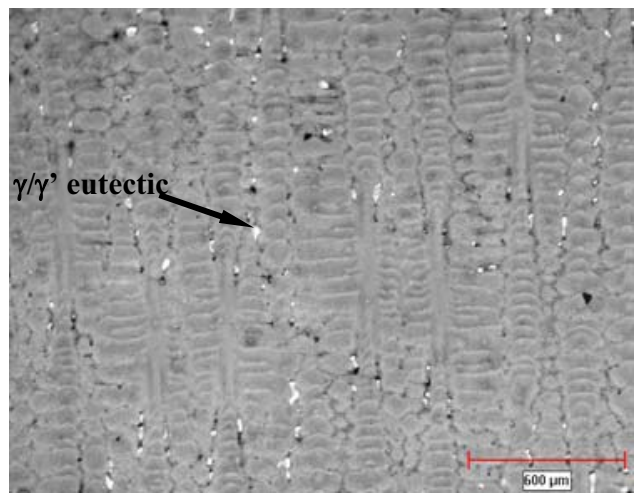

(c) $\mathrm{Base}+\mathrm{C}$

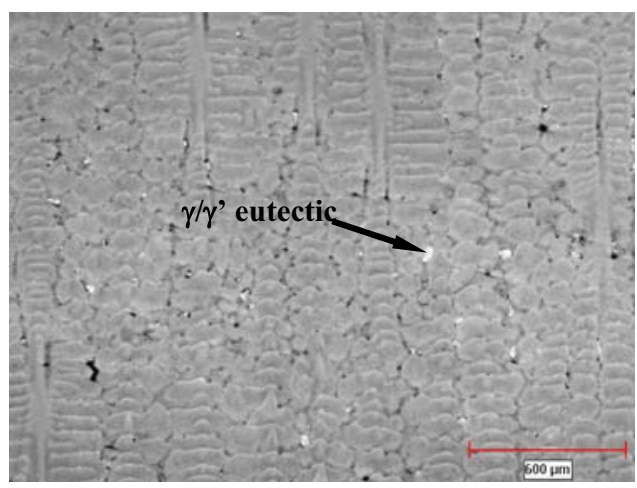

(d) $\mathrm{Base}+\mathrm{B}+\mathrm{C}$

Fig. 2 Optical microstructures of the four as cast alloys. Notice the $\gamma / \gamma^{\prime}$ eutectic in the interdendritic regions; carbides in C containing alloys not detected in low magnified optical micrograph. 


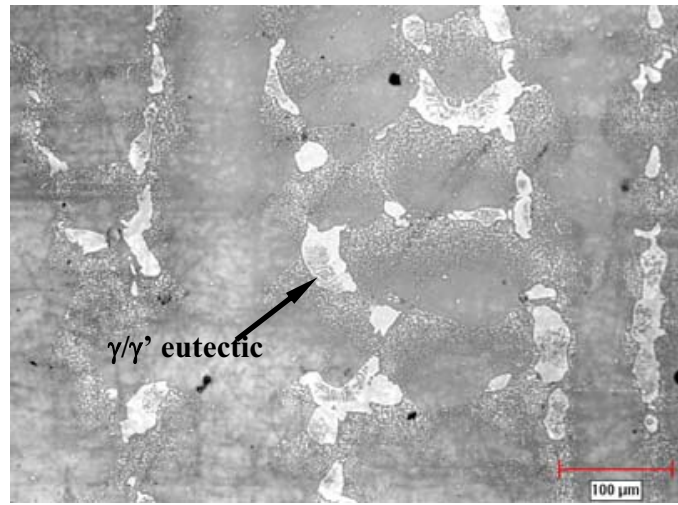

(a) Base

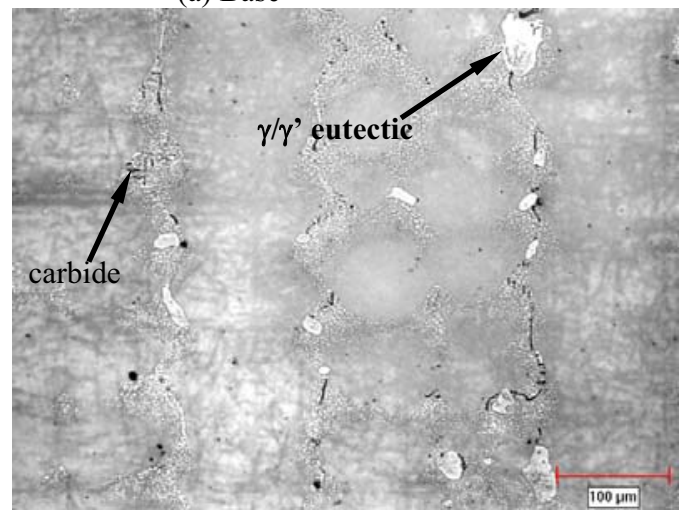

(c) $\mathrm{Base}+\mathrm{C}$

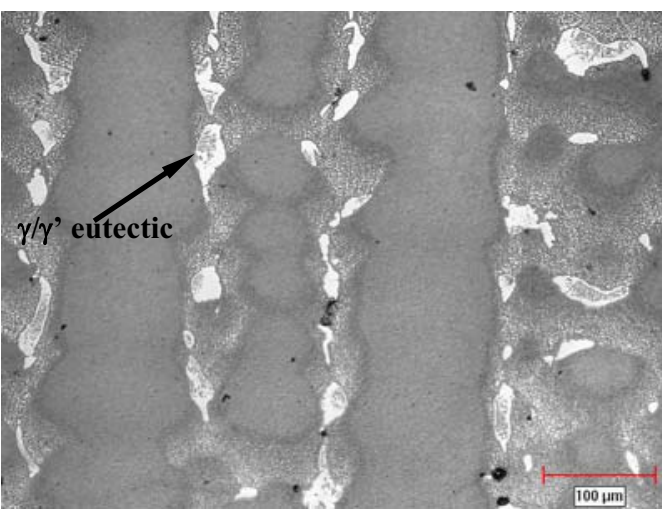

(b) Base+B

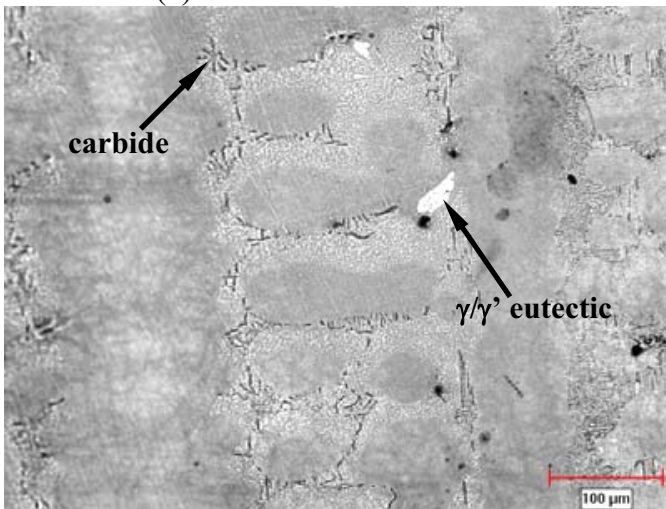

(d) $\mathrm{Base}+\mathrm{B}+\mathrm{C}$

Fig. 3 Optical microstructure of the preweld materials subjected to solution heat treatment and water cooling $\left(1225^{\circ} \mathrm{C} \times 1 \mathrm{~h}+1275 \times 5 \mathrm{~h}\right) / \mathrm{WQ}$.
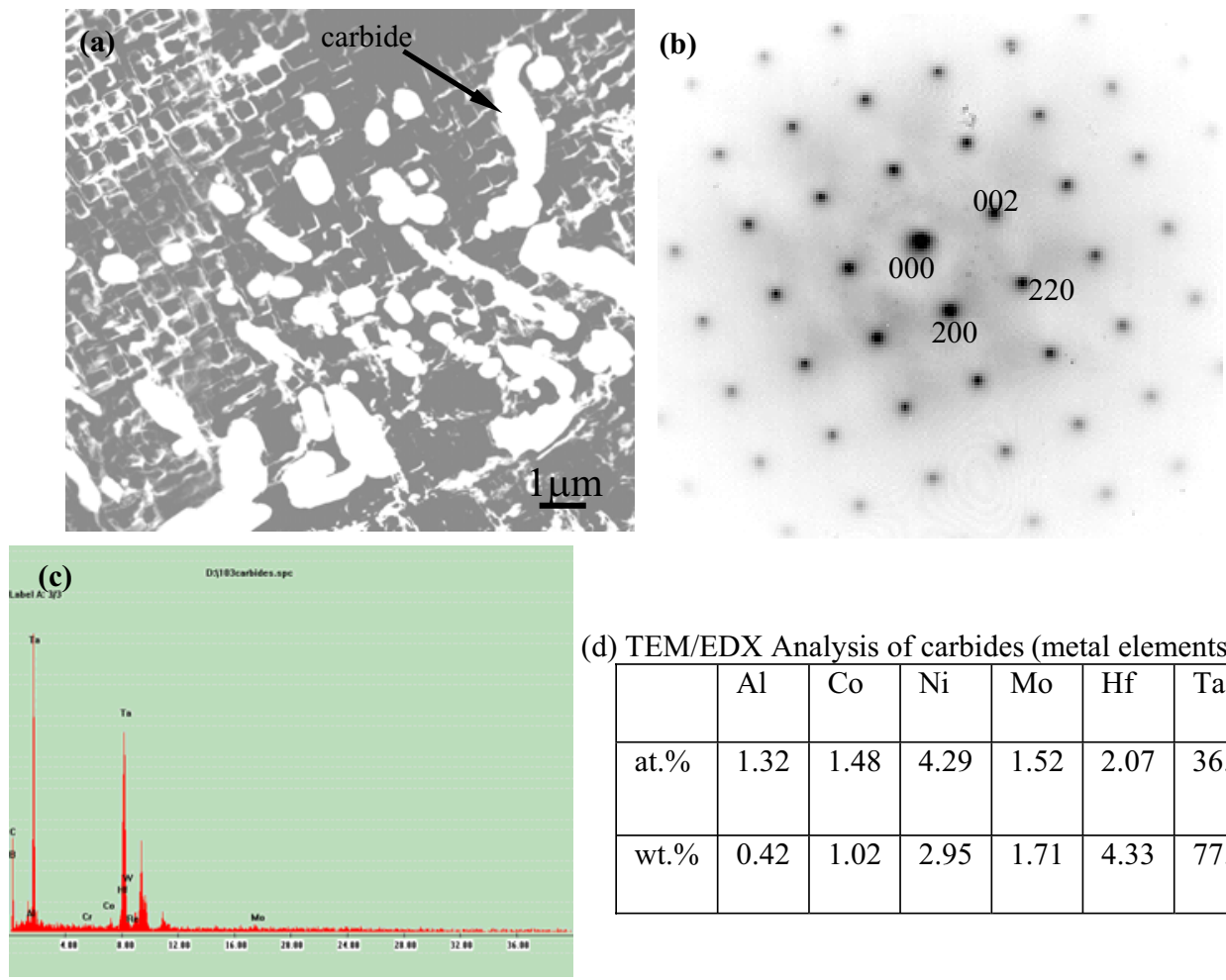

(d) TEM/EDX Analysis of carbides (metal elements analysis only)

\begin{tabular}{|l|l|l|l|l|l|l|l|}
\hline & $\mathrm{Al}$ & $\mathrm{Co}$ & $\mathrm{Ni}$ & $\mathrm{Mo}$ & $\mathrm{Hf}$ & $\mathrm{Ta}$ & $\mathrm{W}$ \\
\hline at.\% & 1.32 & 1.48 & 4.29 & 1.52 & 2.07 & 36.57 & 2.28 \\
\hline wt.\% & 0.42 & 1.02 & 2.95 & 1.71 & 4.33 & 77.6 & 4.9 \\
\hline
\end{tabular}

Fig. 4 (a) TEM image of Ta-rich MC carbides in the carbon extraction replica of base $+\mathrm{B}+\mathrm{C}$ alloy. (b) SAD pattern with [001] axis of MC carbide shown in (a). (c) TEM/EDX spectrum of carbide. 
of $\mathrm{Ni}, \mathrm{W}, \mathrm{Hf}$, Co and Al. Borides were not observed in the Bcontaining alloy, though $\mathrm{B}$ was observed in some of the carbides.

A general SEM secondary electron microstructure of a solution treated Base alloy is shown in Fig. 5a. The higher magnification micrograph of an interdendritic region, marked $\mathrm{A}$ in Fig. 5a and shown in Fig. 5b shows the presence of $\gamma / \gamma^{\prime}$ eutectic in the interdendritic region. Some of the primary $\gamma^{\prime}$ particles dissolved during heat-treatment but reprecipitated as fine cuboid shaped $\gamma$ ' precipitates as shown in the magnified image of region marked B in Fig. 5a and shown in Fig. 5c. Those $\gamma^{\prime}$ precipitates that did not dissolve coarsened during the heat treatment, as shown in the magnified image of interdentritic primary $\gamma^{\prime}$ in Figure 5d. The $\gamma^{\prime}$ morphology in the other 3 solutions treated alloys was similar to that observed in the Base alloy. However, the addition of $\mathrm{C}$ resulted in precipitation of MC type carbides and a significant reduction in the volume fraction of $\gamma / \gamma^{\prime}$ eutectic.

Various microstructural features were quantitatively analysed Table II shows the size and volume fractions of the precipitates in the Base (TMS-75) alloy and the Base $+C+B$ (TMD-103) alloys in the as-cast and the solution treated conditions. The size of the secondary $\gamma^{\prime}$ precipitated particles is seen to be similar in both the alloys, but in the solution treated condition the primary $\gamma^{\prime}$ precipitates are much larger in the Base alloy than those observed in the Base $+\mathrm{B}+\mathrm{C}$ (TMD-103) alloy. As seen in this Table the volume fraction of $\gamma^{\prime}$ precipitate is smaller in the Base $+\mathrm{C}+\mathrm{B}$ (TMD-103) alloy, though its hardness (478 VPN) is about 30 Vickers points more than the Base alloy (448 VPN).

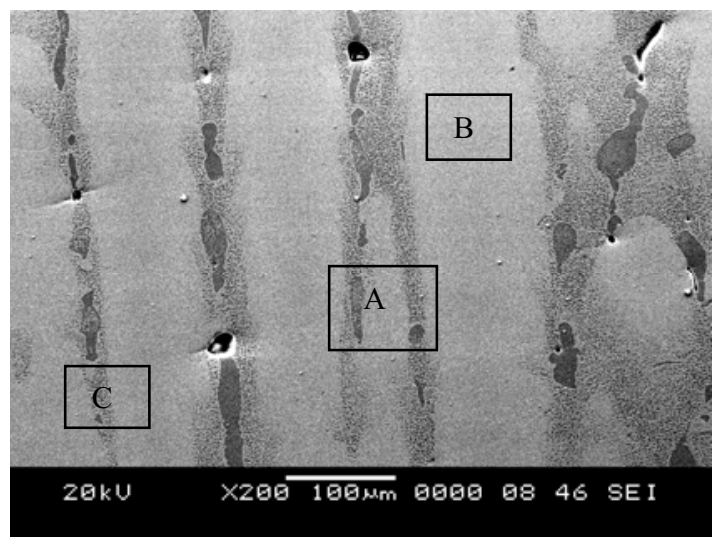

(a)

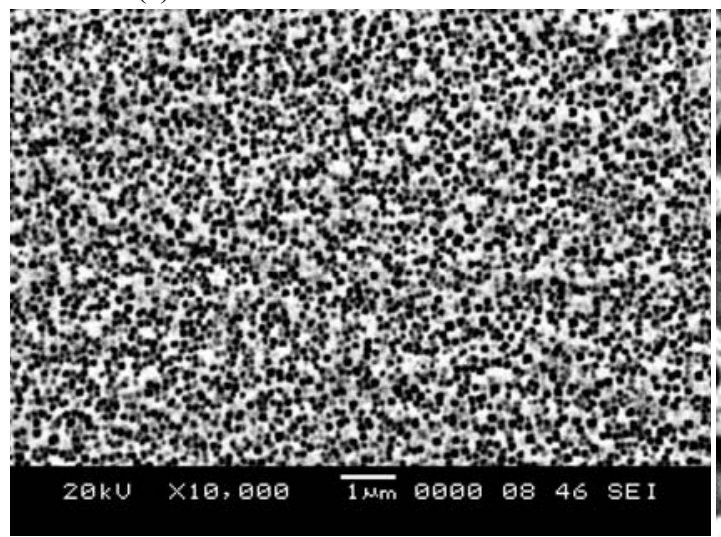

(c) Inset B in a

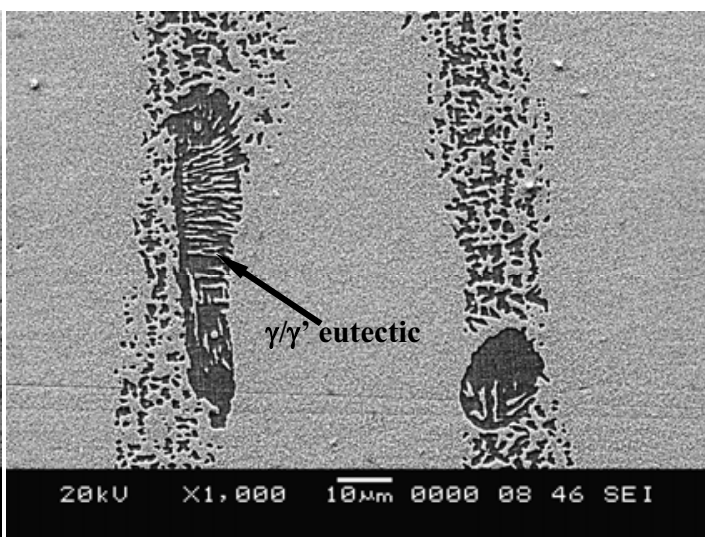

(b) Inset $\mathrm{A}$ in a

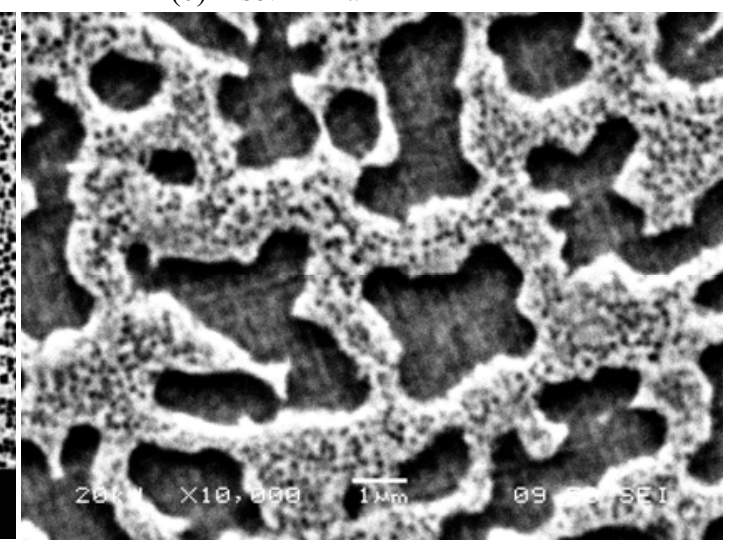

(d) Inset $\mathrm{C}$ in a

Fig. 5 SEM micrographs of the base alloy (ST/WQ). After solution treatment, the primary $\gamma^{\prime}$ in the as cast material dissolve and reprecipitate as fine cuboidal shaped $\gamma^{\prime}$ (shown in c) while the residual grain boundary $\gamma^{\prime}$ become coarser (shown in d).

Table II: Average size and volume fraction of $\gamma^{\prime}$ precipitates in the Base and Base $+\mathrm{B}+\mathrm{C}$ alloys

\begin{tabular}{|c|c|c|c|c|c|c|}
\hline Alloy & & \multicolumn{2}{|c|}{ As cast } & \multicolumn{3}{c|}{ Solution Treated } \\
\hline & & $\begin{array}{c}\gamma^{\prime} \text { size } \\
(\mathrm{nm})\end{array}$ & $\begin{array}{c}\gamma^{\prime} \text { vol. frac. } \\
(\%)\end{array}$ & $\begin{array}{c}\gamma^{\prime} \text { size } \\
(\mathrm{nm})\end{array}$ & $\begin{array}{c}\gamma^{\prime} \text { vol. frac. } \\
(\%)\end{array}$ & $\begin{array}{c}\text { Hardness } \\
\text { VPN }\end{array}$ \\
\hline \multirow{2}{*}{ Base (TMS-75) } & Dendritic core & 0.6 & 58 & 0.19 & 44 & 448 \\
\cline { 2 - 7 } & Interdendritic & 0.78 & 69 & $\begin{array}{c}\text { Sec. } 0.19 \\
\text { Prim. } 2.98\end{array}$ & 55 & \\
\hline \multirow{2}{*}{$\begin{array}{c}\text { Base + B+C } \\
\text { (TMD-103) }\end{array}$} & Dendritic core & 0.63 & 50 & 0.23 & 37 & 478 \\
\cline { 2 - 6 } & Interdendritic & 0.68 & 58 & $\begin{array}{c}\text { Sec. } 0.23 \\
\text { Prim. } 0.70\end{array}$ & 44 & \\
\hline
\end{tabular}


The volume fraction of $\gamma / \gamma^{\prime}$ eutectic was measured in all the four alloys and is given in Table III. It is seen that the addition of $0.005 \mathrm{~B}$ to the base alloy had almost no influence on the volume fractions of $\gamma / \gamma^{\prime}$ eutectic. However, the addition of $0.03 \% \mathrm{C}$ reduced it significantly from $3.03 \pm 0.21 \%$ to $0.68 \pm 0.11 \%$. Similarly, the addition of $0.07 \mathrm{C}$ to the Base alloy reduced it to $0.35 \pm 0.15 \%$. That is, the addition of $\mathrm{C}$ reduced the volume fraction of $\gamma / \gamma^{\prime}$ eutectic and helped induce the formation of MC type carbide phase. Since Ta is a major element in the MC-carbide in these alloys, the formation of $\mathrm{MC}$ would reduce the amount of Ta available for the formation of $\gamma^{\prime}$ which would reduce the volume fraction of $\gamma^{\prime}$ (Table II) as well as that of the $\gamma / \gamma^{\prime}$ eutectic (Table III).

Table III Volume fraction of carbides and $\gamma / \gamma^{\prime}$ eutectic in the four

\begin{tabular}{|l|l|l|}
\hline \multicolumn{3}{|c|}{ alloys (ST/WQ). } \\
\hline Alloys & carbides (\%) & $\gamma / \gamma^{\prime}$ eutectic (\%) \\
\hline Base & & $3.03 \pm 0.21$ \\
\hline Base+B & & $2.98 \pm 0.34$ \\
\hline Base+C & $1.35 \pm 0.14$ & $0.68 \pm 0.11$ \\
\hline Base+B+C & $2.4 \pm 0.19$ & $0.35 \pm 0.15$ \\
\hline
\end{tabular}

Metallography of Welds and Evaluation of Weldability
Fig 6 shows an optical micrograph of the weld section in the Base alloy, with a nail-head shape which is typical of an E-beam weld. As seen in this figure, HAZ and weld metal micro-fissures are present, and were observed in all the four alloys, the present communication is, however, only concerned with HAZ cracking. As seen in Fig. 6, the HAZ micro-fissuring in all the alloys was interdendritic and originated close to the fusion line, but never in the weld metal.

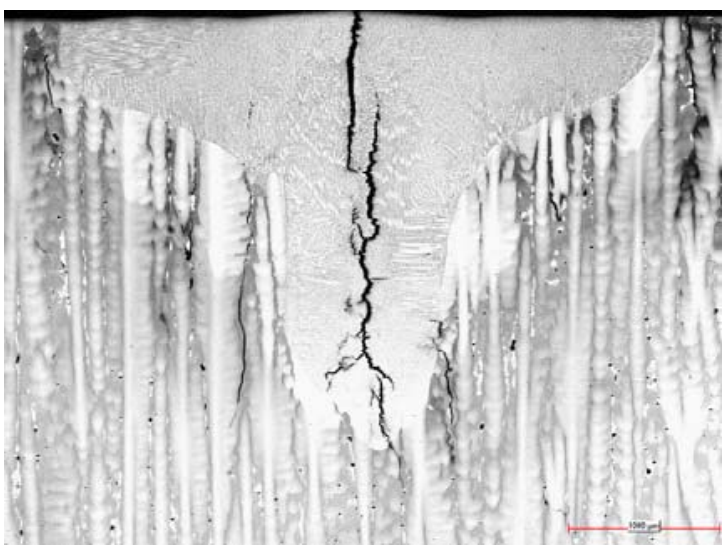

Fig. 6 Macrograph of an electron beam weld in TMS-75

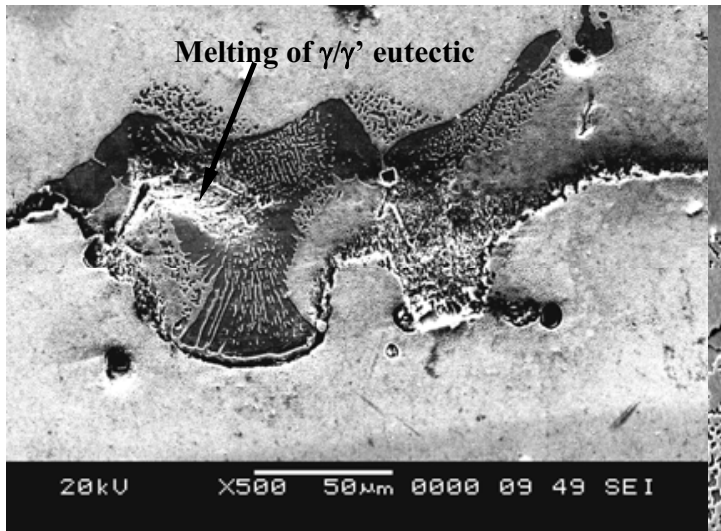

(a) Base

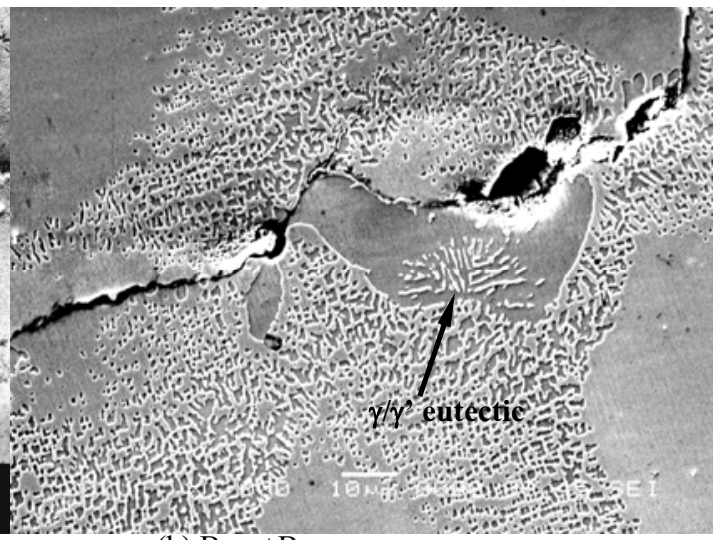

(b) $\mathrm{Base}+\mathrm{B}$

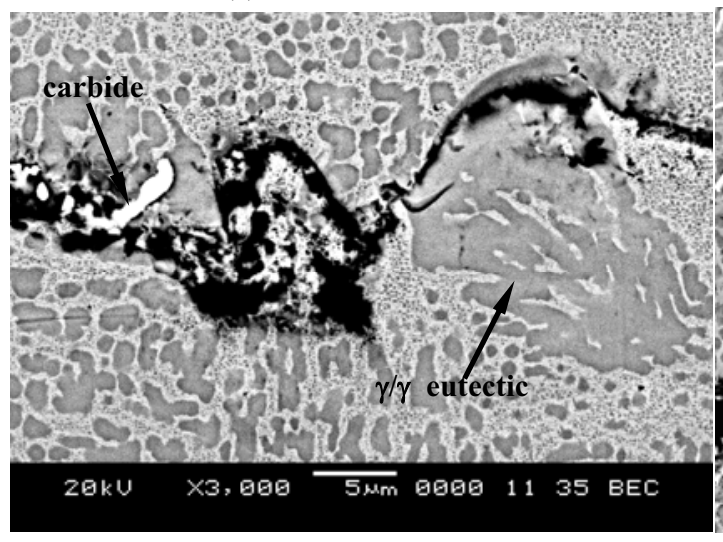

(c) Base $+\mathrm{C}$

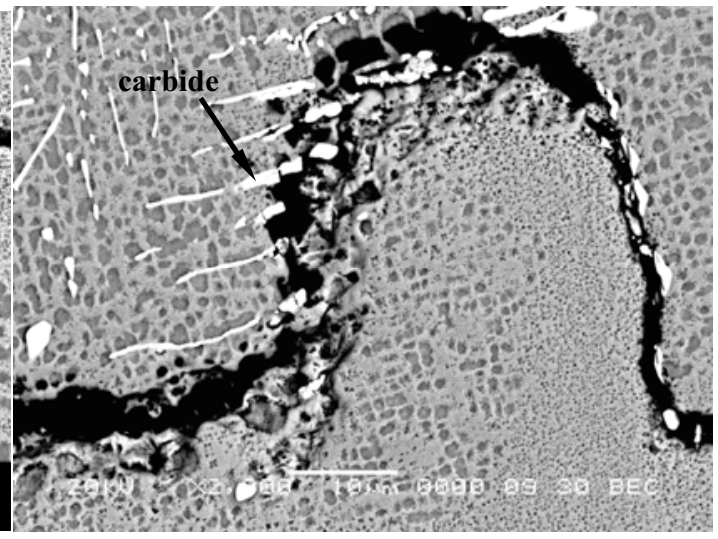

(d) $\mathrm{Base}+\mathrm{B}+\mathrm{C}$

Fig. 7 Cracks in the heat affected zone of TMS-75 and the modified alloys. Notice the melting of $\gamma / \gamma^{\prime}$ eutectic (shown in a, b, and c) and the constitutional liquation of carbides (shown in $\mathrm{c}$ and $\mathrm{d}$ ). 
The HAZ microstructures of all the four alloys were extensively examined by SEM and representative micrographs are shown in Fig 7(a-d). As seen in Figure 7a and b, micro-fissuring in both the Base and Base $+B$ alloys was mainly associated with the $\gamma / \gamma^{\prime}$ eutectic, which would remain liquid over a wider temperature range. This liquid will be subjected to thermal stresses evolving from the cooling cycle after passage of the electron beam, which would induce microfissuring. It should be noted that borides were not specifically observed in the boron containing alloy.

In the Base $+\mathrm{C}$ alloy also some micro-fissuring was associated with the eutectic phase, however, a significant amount constitutional liquation of $\mathrm{MC}$ carbide was also observed, as shown in Fig7(c). As listed in Table III, the $\mathrm{C}$ addition reduced the eutectic volume fraction from $3 \%$ in the Base alloy, to about $0.7 \%$ in the Base $+\mathrm{C}$ alloy. Similarly in the $\mathrm{Base}+\mathrm{B}+\mathrm{C}$ alloy, microfissuring was associated with $\gamma / \gamma^{\prime}$ eutectic liquation and constitutionally liquated $\mathrm{MC}$ carbide, an example of the latter is shown in Fig. 7d.

The HAZ cracking susceptibility of all the four alloys was determined by measuring the average total crack length (Av TCL) on eight weld cross sections of each alloy. Fig 8 shows the Av. TCL values along with $2 \sigma$ (standard deviation) per section for the four alloys in the solution treated condition. It is seen that the addition of $\mathrm{B}$ to the Base alloy increased the micro-fissuring susceptibility by almost $60 \%$, whereas the addition of $\mathrm{C}$ to Base alloy reduced it by about $75 \%$. Similarly in the Base $+B+C$ alloy, micro-fissuring behaviour was significantly attenuated by the $0.07 \% \mathrm{C}$ addition. That is, the Av. TCL reduced from $2.36 \mathrm{~mm}$ to $0.36 \mathrm{~mm}$.

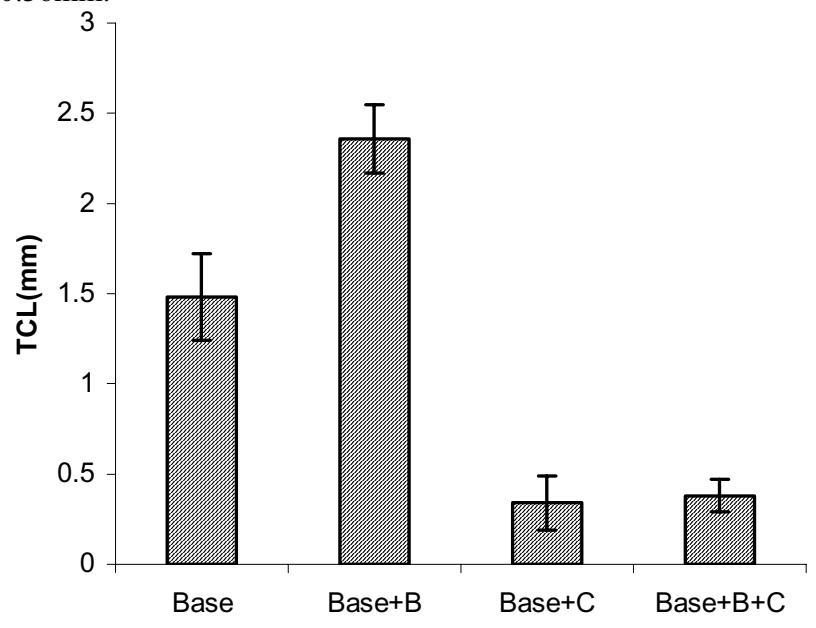

Fig. 8 The effect of composition on the total crack length (Av. $\mathrm{TCL})$ in $\mathrm{HAZ}$ at room temperature $(44 \mathrm{KV}, 13 \mathrm{~mA}, 25 \mathrm{~cm} / \mathrm{min}$.).

\section{Discussion}

In the Base alloy, the main microstructural phase associated with HAZ micro-fissuring was observed to be the $\gamma / \gamma^{\prime}$ eutectic, whose total volume fraction in the Base alloy was about 3\%. Fig 7(a) shows micro-fissuring intimately associated with the liquated eutectic $\gamma / \gamma^{\prime}$. MC carbides were not present in the Base alloy due to the extremely low $\mathrm{C}$ concentration, and thus for this alloy carbides do not play a part in its micro-fissuring behaviour. Similarly in the case of the Base+B alloy, (Fig 7b), the absence of
MC carbides, along with no evidence for borides to be present, leads to the conclusion, based on the metallographic observations, that the $\gamma / \gamma^{\prime}$ eutectic again plays the major role in micro-fissuring of HAZ around welds.

In the case of the Base $+\mathrm{C}$ alloy, Fig 7(c), the presence of an additional micro-constituent, besides the $\gamma / \gamma^{\prime}$ eutectic, suggests the possibility for two factors to influence the HAZ micro-fissuring on grain boundaries. In this case, liquation cracking can be either due to the presence of the lower melting point $\gamma / \gamma^{\prime}$ eutectic, and/or constitutional liquation of secondary constituents. As shown in micrograph in Fig 7(c), in the Base $+\mathrm{C}$ alloy microfissuring due to the constitutional liquation of the Ta rich MC carbides along with that caused by liquation of $\gamma / \gamma^{\prime}$ eutectic was observed. It should be noted from Table III, that the addition of $\mathrm{C}$ considerably reduced the volume fraction of $\gamma / \gamma$ 'eutectic constituent, and thus it would have a less detrimental effect in the Base $+\mathrm{C}$ alloy compared to that observed in the Base and Base $+\mathrm{B}$ alloys. This observation is also reflected in the Av. TCL values reported in Fig 8, where the $\mathrm{C}$ containing alloy had an Av. TCL value of $0.34 \mathrm{~mm}$ compared to the Base $(1.48 \mathrm{~mm})$ and Base + B alloy $(2.36 \mathrm{~mm})$.

The same conclusion can be made for the Base $+\mathrm{B}+\mathrm{C}$ alloy, where again, as shown in Fig 8, the Av. TCL value was similar to that observed in the Base $+\mathrm{C}$ alloy. This reflects the beneficial effect of $\mathrm{C}$ on HAZ micro-fissuring observed by Benhaddad et al [5], in wrought alloy 718 , where the $\mathrm{C}$ addition offset the detrimental effects of both B and P.

It should also be noted, however, that the $\mathrm{C}$ addition not only reduces the Av. TCL values of the $\mathrm{Base}+\mathrm{C}$ alloy relative to the Base alloy, but even in the presence of $\mathrm{B}$ in the Base $+\mathrm{C}+\mathrm{B}$ alloy, and $\mathrm{C}$ addition attenuates the detrimental effect of $\mathrm{B}$. Benhaddad et al [5] attributed this effect in wrought 718 to site competition at the grain boundaries between competing segregating species as proposed by Erhart and Grabke [11]. In their research it was shown that $\mathrm{C}$, for example, can displace $\mathrm{P}$ from grain boundaries in plain $\mathrm{C}$ and $\mathrm{Cr}$ alloyed steels. This theory however is at variance with the intensification of grain boundary segregation proposed by Guttmann [12] for ternary additions to a binary alloy. In the present case, however, it is more likely that Erhart and Grabke's theory is more relevant due to the small $\mathrm{C}$ addition made to the present alloys. Guttmann's theory is more likely to be relevant where substantial $(>>1 \%)$ additions of the ternary element are made rather than $<0.1 \% \mathrm{C}$, as is the case in the present alloys.

Another contributing factor relative to the $\mathrm{C}$ addition is the potential effect of the element on the solidification path of the alloys. Thompson et al [13] have investigated the influence of C on solidification via increased volume fraction of carbides, ensuring the liquid film is retained to lower temperatures relative to a smaller amount of liquid. In addition they [13] have also shown that $\mathrm{C}$ can influence the solidification path depending on the $\mathrm{C} / \mathrm{Nb}$ ratio. Floreen et al [14] have proposed the following solidification path for Alloy 625:

(a) High $\mathrm{C} / \mathrm{Nb}$ ratio leads to the formation of $\gamma+\mathrm{NbC}$, with no Laves phase.

(b) Intermediate $\mathrm{C} / \mathrm{Nb}$ ratio leads to the formation of $\gamma+\mathrm{NbC}$ rather than that of Laves phase at the end of solidification.

(c) Low $\mathrm{C} / \mathrm{Nb}$ ratio leads to the formation of $\gamma+$ Laves phase, with no $\mathrm{NbC}$ being formed. 
In a similar investigation by Dupont et al [15], $\mathrm{C}$ additions were found to increase the initiation of the reaction, $L \rightarrow \gamma+$ Laves phase, and a decrease in the temperature range of the primary $\mathrm{L} \rightarrow$ $\gamma$ reaction. They also observed considerable improvements in solidification cracking behavior at higher $\mathrm{C}$ levels during Varestraint testing, using the maximum crack length as the failure criterion. Thus, by increasing the $\mathrm{C}$ level Dupont et al have suggested that it should be possible to influence the solidification path and in turn reduce the solidification range in alloy 718 and consequently minimize micro-fissuring, similar to an alloy with a low $\mathrm{C}$ or $\mathrm{B}$ concentration. In the present case the beneficial effect of carbon may have been associated with the formation of the Ta rich MC carbide at high temperature, reducing the availability of Ta to form the $\gamma / \gamma^{\prime}$ eutectic, in a manner similar to that reported by Dupont et al.

Another minor element to consider relative to micro-fissuring is boron. SIMS analysis has shown in both cast and wrought IN718 that segregation of B to grain boundaries plays a dominant role in cracking of the alloy [8-11]. In the present case two of the alloy contained B levels of 0.005 wt. \%, (Base + B) and 0.015 wt. \%, $(\mathrm{Base}+\mathrm{B}+\mathrm{C})$. To evaluate the role of segregation of $\mathrm{B}$, SIMS studies are planned.

\section{Summary and Conclusions}

Four DS Ni-based Superalloys, Base, Base $+B$, Base + C and Base $+\mathrm{B}+\mathrm{C}$, were electron beam welded and the heat affected zone micro-fissuring examined in terms of the phases present prior to and after welding. Quantitative evaluation of micro-fissuring was made using the value of Av. TCL per section:

1) In the Base alloy, carbides were absent and the main phase responsible for HAZ micro-fissuring was observed to be the $\gamma / \gamma^{\prime}$ eutectic. This is a low melting point constituent and would have remained liquid to lower temperatures where thermal stresses would occur initiating microfissuring at the grain boundaries containing liquated $\gamma / \gamma^{\prime}$ eutectic.

2) In the Base+B alloy, borides were not observed and the microfissuring was associated with the liquated eutectic phase.

3) In the Base $+\mathrm{C}$ alloy, $\mathrm{MC}$ carbides also partly contributed to micro-fissuring, but the $\mathrm{C}$ addition attenuated the micro-cracking susceptibility, due to the reduced volume fraction of $\gamma / \gamma^{\prime}$ eutectic in the alloy.

4) Similarly in the Base $+B+C$ alloy, the $C$ addition again offset the detrimental effects of $\mathrm{B}$, as shown by the reduced Av. TCL values

\section{Acknowledgements}

The authors would like to thank Dr. Hiroshi Harada for providing the alloys and Bristol Aerospace for doing the welding. The authors gratefully acknowledge the financial support by NSERC of Canada and the University of Manitoba.

\section{References}

\section{T. Hino, et al., Superalloys 2000, 729-736.}

2. T. Kobayashi, et al., Proceedings of the $4^{\text {th }}$ International Charles Parsons Turbine Conference, 766-773.
3. T. Kobayashi, et al., Superalloys 2000, 323-328.

4. T. Kobayashi, et al., Proceedings of the $6^{\text {th }}$ Liege Conference, Materials for Advanced Power Engineering, (1998), 1079-1087.

5. S. Benhadad, N.C. Richards and M.C. Chaturvedi, "The Influence of Minor Elements on the Weldability of an Inconel 718-type Superalloy", Metallurgical and Materials Transactions, 33A (2002), 2005-2017.

6. T.J. Kelly, "Elemental Effects on Cast 718 Weldability", Welding Journal, 69 (2) (1989), 44s-51s.

7. X. Huang, N.L. Richards and M.C. Chaturvedi, "Effect of Homogenization Heat Treatment on the Microstructure and Heat Affected Zone Microfissuring in Welded Cast Alloy 718", Metallurgical and Materials Transactions A, 27A (1996), 785790.

8. X. Huang, et al., "The Effect of Grain Boundary Segregation of Boron in Cast Alloy 718 on HAZ Microfissuring - A SIMS Analysis", Acta Materialia, 45 (8) (1997), 3095-3107.

9. W. Chen, M.C. Chaturvedi and N. L. Richards, "Effect of Boron Segregation at Grain Boundaries on Heat-Affected Zone Cracking in Wrought Inconel 718", Metallurgical and Materials Transactions, 32A (2001), 931-939.

10. H. Guo, M.C. Chaturvedi and N. L. Richards, "The Effect of B Concentration and Grain Size on Weld HAZ Microfissuring in Inconel 718 Base Superalloys", Science and Technology of Welding and Joining, 4 (1999), 257-274.

11. H. Erhart and H.J. Grabke, "Equilibrium Segregation of Phosphorus at Grain Boundaries of Fe-P, Fe-C-P, Fe-Cr-P, and Fe-Cr-C-P Alloys", Metal Science, 15 (1981), 401-408.

12. M. Guttmann, "Equilibrium Segregation in a Ternary Solution: A Model for Temper Embrittlement", Surface Science, 53 (1975), 213-227.

13. R.G. Thompson, B. Radhakrishnan, and D.E. Mayo, "The Relationship between Carbon Content, Microstructure, and Intergranular Liquation Cracking in Cast Nickel Alloy 718", Metallurgical and Materials Transactions A, 22A (1991), 557567.

14. S. Floreen, G.E. Fuchs, and W.J. Yang, “ The Metallurgy of Alloy 625", Superalloys 718, 625, 706 and Various Derivatives, ed. E. A. Loria (Warrendale, PA, TMS, 1994), 13-17.

15. J.N. Dupont, C.V. Robino, and A.R. Marder, "Solidification and Weldability of Nb-Bearing Superalloys", Welding Journal, 77 (10) (1998), 417s-431s. 
